\title{
INMIGRANTES Y REFUGIADOS EN UN MUNICIPIO DE LA RETAGUARDIA REPUBLICANA: ELCHE, 1936-1940 ${ }^{1}$
}

\author{
Salvador Palazón Ferrando \\ José Antonio Miranda Encarnación
}

\begin{abstract}
RESUMEN
Este artículo pretende mostrar el carácter que tuvo Elche, durante la Guerra Civil, como importante núcleo receptor de refugiados procedentes de las provincias bajo control de la República a medida que iba avanzando el frente de guerra; así como los cambios que por causa de aquélla se produjeron en la corriente inmigratoria tradicional hacia este municipio.
\end{abstract}

\section{SUMMARY}

This paper tryes to show the character of Elche like important receipt nucleus of refugees, in the time of Civil War, from tre provinces in the Republican area that suffer the going of the war; in the same way, the changes produced cause of it in the traditional migratory trends to this council. The source used have been the municipal mailing from 1936 to 1940 , the local tabloids and the municipal census.

La guerra civil española, desde sus comienzos, obligó a muchos españoles a abandonar sus lugares de residencia, huyendo de las calamidades del conflicto, de los peligros del frente o de las represalias políticas. En la España republicana, una de las provincias más alejadas de los combates fue Alicante y, por ello, se convirtió en un destino idóneo para estos refugiados. Dentro de ella, Elche era uno de los municipios de mayor entidad e importancia económica, de ahí que resulte fundamental conocer cual fue su papel en la recepción de esta corriente de evacuados. Con nuestra investigación pretendemos demostrar que fue un importante núcleo de acogida, así como analizar las características de esta población desplazada. En relación con este tema nos hemos ocupado también de estudiar la corriente inmigratoria, buscando las repercusiones que en ella tuvo la contienda bélica.

1 Comunicación presentada a las Jornadas sobre Movimientos migratorios provocados por la guerra civil española, Universidad de Salamanca, 15-17 diciembre de 1988, organizadas por el Ministerio de Cultura, Archivo Histórico Nacional, Sección Guerra Civil. 


\section{Los refugiados en Elche}

El carácter que Elche tuvo como municipio receptor de refugiados lo podemos verificar a través de la Correspondencia de la Alcaldía y de la Prensa local, fuentes ambas que nos facilitan noticias pormenorizadas sobre la llegada de gentes que huyen de la guerra. Estas noticias nos permiten conocer sus lugares de procedencia, y nos muestran la evidente conexión entre estos desplazamientos y el avance de las tropas sublevadas (véase fig. 1).

Ya en octubre de 1936, Elche recibió un importante contingente de evacuados procedentes de las provincias de Badajoz, Cáceres, Toledo, Ávila, Madrid y Córdoba ${ }^{2}$. A partir de entonces, otras provincias se fueron añadiendo a esta lista. Tenemos constancia de que en febrero de 1937 llegaron desde Málaga $^{3}$, y de la presencia de refugiados asturianos al menos desde noviembre de ese mismo año. En el verano de 1938 aparecen consignados también evacuados granadinos y jienenses ${ }^{4}$.

Por el momento resulta imposible saber el número total de evacuados que Elche acogió. Podemos estimar, sin embargo, que fue cuantioso, pues no en vano a los pocos meses de estallar la guerra ya había recibido cerca de dos mil refugiados; y ello a pesar de los múltiples inconvenientes y limitaciones que encontraba cualquier desplazamiento interprovincial durante la guerra y que fueron creciendo conforme esta avanzaba ${ }^{5}$.

El organismo encargado de acoger y amparar a esta población era el Comité Local de Refugiados, dependiente del Ayuntamiento de Elche y a las órdenes del Comité Provincial. En esta tarea se vería auxiliado por la delegación ilicitana del Socorro Rojo Internacional.

Para hacer frente a la creciente carga económica que suponían los refugiados, las instituciones de las que dependían tuvieron que arbitrar medidas de diverso tipo, aunque quizá la más importante fuera el establecimiento de un impuesto del $1 \%$ sobre todas las ventas al por mayor realizadas en el municipio y no destinadas al Ministerio de la Guerra ${ }^{6}$.

Además del problema de su manutención, estos evacuados planteaban la necesidad de ser alojados. Para solventar tal cuestión se recurrió tanto a la solidaridad del pueblo ilicitano como al uso de los inmuebles pertenecientes al Ayuntamiento. De esta forma, los recién llegados se distribuyeron por todo el municipio, en la ciudad y en las partidas

2 En una nota aparecida en El Obrero de 11 de octubre de 1936, n. ${ }^{\circ}$ 524, p. 1, el Frente Popular de Alicante solicitaba a todas las organizaciones obreras alicantinas que le remitiesen una relación nominal de todos aquellos camaradas que, a partir del 5 de septiembre, hubiesen evacuado los pueblos de Badajoz, tomados por los facciosos y se hubiesen refugiado en la provincia de Alicante.

Otra noticia aparecida también en El Obrero una semana más tarde (18-X-1936, n. ${ }^{\circ}$ 525, p. 4) decía: «Los refugiados en Elche. Varias expediciones de refugiados de las provincias de Cáceres, Badajoz y Toledo han llegado a nuestra Ciudad. Ya suman unos dos mil. Elche los ha acogido en su seno y está dispuesto a admitir a todos los que por necesidades de guerra hagan falta. (...)».

3 En El Obrero de 14 de febrero de 1937, n. ${ }^{\circ}$ 542, p. 5, puede leerse en una noticia dedicada a la caída de Málaga: «(...) Hasta Alicante nos llegan diariamente numerosos camaradas evacuados. Su aspecto es completamente mísero, vienen hacinados en camiones. (...)».

4 Varios telegramas referidos a refugiados de estas dos provincias aparecen entre la Correspondencia de la Alcaldía, Leg. D-87, Archivo Histórico Municipal de Elche (AHME).

5 El 17 de octubre de 1936, el Gobernador Civil de Alicante transmitía por telegrama al Alcalde de Elche, los acuerdos tomados por el Comité Nacional de Refugiados, entre estos acuerdos destacan: «Los Ayuntamientos no deben proceder evacuación ninguna persona hacia otra provincia sin permiso autoridad militar competente»; «Para verificar evacuación es absolutamente indispensable el conocimiento y autorización del Comité de Refugiados que funciona en Presidencia Consejo de Ministros»; "De no cumplir estos requisitos no podrá ser utilizado el ferrocarril como medio de transporte» (AHME, Leg. D-86).

6 Un aviso del Comité Local de Refugiados fechado en Elche a 21 de abril de 1938 transmitía esta nueva Orden de la Presidencia del Consejo de Ministros (Elche Rojo, n. 54 y El Obrero, n. ${ }^{\circ}$ 604, ambos de 24 de abril de 1938). Según otra Orden de la Presidencia del Consejo de Ministros de 26 de octubre de 1936, se establecieron, como medio de recaudar fondos, los «Tikets Pro-Refugiados», de uso obligado para público y comerciantes. 
FiguRA 1. Frente de guerra y refugiados en Elche. A) Frente de guerra en otoño de 1936; B) frente de guerra en marzo de 1937. Fecha de llegada desde las provincias marcadas: 1, octubre de 1936; 2, febrero de 1937; 3, verano de 1937.

rurales, aunque todo parece indicar que a estas últimas acudió un mayor contingente ${ }^{7}$. También en el campo se ubicaron tres colonias infantiles que acogían a un total aproximado de ciento cincuenta niños procedentes de las zonas más castigadas por la guerra, sobre todo de las que sufrían violentos bombardeos. Estos albergues dependían de la Delegación Regional de Colonias de Infancia Evacuada, con sede en Valencia, y sabemos que, a partir de 1938, vieron sus recursos limitados y padecieron serias deficiencias de abastecimiento . $^{2}$ Aún así, subsistieron algunos meses tras el final de la guerra, en espera de que los familiares de los niños acudiesen a hacerse cargo de ellos 9 . Por lo que respecta al resto de refugiados, los datos del Padrón Municipal de Habitantes de 1940 nos demuestran que aquellos habían abandonado en su práctica totalidad Elche, ya que no aparece reflejado

7 De ahí este párrafo, continuación de la noticia aparecida en El Obrero (n. $\left.{ }^{\circ} 525\right)$ sobre los refugiados en Elche (véase nota 2): «(...) Debemos consignar un dato que en justicia lo merece. El gesto de los campesinos que en masa ha venido a llevarse refugiados a sus casas». Datos sobre la distribución por el municipio de los evacuados también aparecen en la Correspondencia Municipal, AHME, Legs. D-87, D-88, D-97 y D-98.

8 Hemos encontrado telegramas (fechados en abril, junio y julio de 1938) del Alcalde de Elche a los responsables en Valencia de estas colonias, aludiendo reiteradamente a la falta de fondos para su sustento, AHME, Legs. D-105 y D-107.

9 La Alcaldía de Elche dirigió, en agosto de 1939, una carta a un vecino de Madrid informándole de la presencia de sus hijos en la Colonia n. ${ }^{\circ}$ 9. Esta carta, a su vez, nos sirve de ejemplo sobre los desplazamientos que tuvieron que sufrir los niños evacuados, ya que estos niños madrileños antes de llegar a Elche habían sido enviados a Orihuela, AHME, Leg. D-100. 
ningún aporte demográfico extraprovincial de la entidad que tuvo el colectivo de evacuados en el Municipio.

Una fuente fundamental para ampliar nuestro conocimiento de la población desplazada son los informes que cada uno de los alcaldes de aquellos municipios que eran cabeza de partido judicial estaban obligados a enviar al Comité Provincial de Refugiados. Este organismo pertenecía al Departamento de Asistencia Social y Sanidad del Comité Popular Provincial de Defensa de Alicante (bajo las órdenes del Gobernador Civil). En esos informes, que todavía no han podido ser encontrados, aparecían detallados: la fecha de llegada de las expediciones de refugiados, sus nombres, edades, profesiones, lugares de procedencia y el régimen de vida que desarrollaban ${ }^{10}$.

\section{La corriente inmigratoria según el padrón municipal de habitantes de 1940}

Sirviéndonos de los datos del Padrón Municipal de Habitantes, elaborado el 31 de diciembre de 1940, y extraídos mediante un vaciado al cien por cien, podemos conocer las características generales de la inmigración en Elche durante el período anterior a la guerra civil (1930-1935) y durante la inmediata posguerra (1939-1940) ${ }^{11}$. De este modo, intentamos apreciar si el conflicto provocó cambios sustanciales en la corriente inmigratoria tradicional hacia el municipio ilicitano.

\section{Lugares de origen de los inmigrados}

Las provincias de Alicante y Murcia destacan de manera excepcional entre todas las demás. Durante toda la década de los años treinta, la provincia de Alicante aporta más de la mitad de los no nacidos en Elche que aparecen empadronados en 1940; mientras que los llegados de Murcia oscilan en torno al 20\%. El resto se reparte entre las demás provincias con proporciones mínimas, inferiores siempre al 3\%, y salvo Albacete, Almería, Barcelona, Córdoba, Granada, Madrid y Valencia, todas por debajo del 1\%. Sin embargo, se aprecia cierta evolución desde los años 1930-35 hasta los de posguerra; evolución caracte-

10 A estas cuestiones aludía el oficio que el Departamento de Asistencia Social y Sanidad del Comité Popular Provincial de Defensa de Alicante dirigió al Ayuntamiento de Elche con fecha de 16 de diciembre de 1936: «(...) En el plazo máximo de quince días a partir de la fecha de esta circular, todos los Alcades de cabeza de Partido judicial enviarán al Comité Provincial de Refugiados, relación de todos los alojados que existan en los pueblos de su jurisdicción. En dichas listas harán constar la fecha en que llegó cada una de las expediciones que haya en el pueblo, nombre y apellidos, edad, oficio y procedencia, entendiendo por procedencia el lugar donde desarrollaban su vida normal. Además se hará constar el régimen de vida que desarrollan los refugiados, si viven independientes merced al fruto de su trabajo, si viven en colectividad y si son o no racionados por los respectivos Comités. Igualmente serán reflejadas las expediciones de niños si en el pueblo las hubiere. Adjuntamente le mandamos impresos, con los cuales le será más fácil la labor. (...)». AHME, Leg. D-98.

11 En una ciudad de 46.596 habitantes donde los inmigrantes suponían el 23\% de su población en 1940, resulta interesante conocer de que modo la guerra civil había influido en la corriente inmigratoria tradicional, o sea, en aquella que tenía sus orígenes en causas económicas. Para ello, el instrumento más útil del que disponíamos era el Padrón Municipal de Habitantes de 1940. Este Padrón nos ofrece tanto una instantánea de la población inmigrada residente en Elche en esos momentos como la tendencia seguida, en líneas generales, por la inmigración a lo largo de la década de 1930, ya que si algunos de los que llegaron a Elche en fechas anteriores no aparecen registrados, el resto, los que sí aparecen, constituyen una muestra lo suficientemente representativa. De la información que nos proporciona esta fuente quizá donde menor precisión se advierte es en el apartado dedicado a la profesión (importante número de «sin especificar») y en el titulado «tiempo de residencia en el municipio» (tendencia al redondeo de las cifras en los años terminados en cero y cinco). 
FiguRA 2. Distribución de los inmigrados residentes en Elche en 1940, según período de llegada y lugar de origen.

CUADRO I

DISTRIBUCIÓN DE LOS INMIGRADOS EN ELCHE SEGÚN SU ORIGEN (en tantos por ciento)

\begin{tabular}{|lrrr|}
\hline Origen & $\mathbf{1 9 3 0 - 3 5}$ & $\mathbf{1 9 3 6 - 3 9}$ & $\mathbf{1 9 3 9 - 4 0}$ \\
\hline Alicante & 55,15 & 54,75 & 52,19 \\
Murcia & 27,23 & 23,77 & 19,68 \\
Resto de España & 15,55 & 20,24 & 26,39 \\
Extranjero & 2,07 & 1,24 & 1,74 \\
Total & 100,00 & 100,00 & 100,00 \\
Total Cifras absolutas & 2.802 & 1.775 & 1.265 \\
\hline
\end{tabular}

rizada por un aumento relativo de la presencia de inmigrantes del resto de España, frente a una clara disminución de los aportes de Murcia y, en menor medida, de Alicante (véase Cuadro I y Fig. 2), no porque decaiga el volumen de llegadas de estas dos provincias sino por el aumento de los procedentes de las otras.

Dentro de la provincia de Alicante, dos comarcas son los principales focos de emigración con destino a Elche: el Bajo Segura y el Vinalopó Medio. Entre ambas proporcionan durante toda la década, más de las tres cuartas partes del total de inmigrados provinciales en Elche, aunque su posición relativa cambió con la guerra, pues si antes de ella el Bajo Segura era la comarca que más individuos aportaba, a partir de 1936 se vio rebasada por el 


\begin{tabular}{|lrrr|}
\hline Comarcas & $\mathbf{1 9 3 0 - 3 5}$ & $\mathbf{1 9 3 6 - 3 9}$ & $\mathbf{1 9 3 9 - 4 0}$ \\
\hline Bajo Segura & 48,86 & 32,51 & 37,12 \\
Vinalopó Medio & 28,60 & 45,88 & 40,30 \\
Campo de Alicante & 7,83 & 9,87 & 11,96 \\
Bajo Vinalopó & 5,56 & 6,17 & 5,15 \\
Otras & 9,15 & 5,57 & 5,47 \\
Total & 100,00 & 100,00 & 100,00 \\
Total Cifras absolutas & 1.545 & 972 & 660 \\
\hline
\end{tabular}

FiguRA 3. Origen comarcal de los inmigrados provinciales en Elche, según el período de llegada.

Vinalopó Medio. Del resto de comarcas, tan sólo presentan aportes importantes el Campo de Alicante y la propia comarca de la que Elche es cabecera comarcal, el Bajo Vinalopó, con cifras relativamente superiores al 5\%, mientras que la evolución del contingente procendente de la primera es claramente ascendente, los llegados desde Crevillente y Santa Pola mantuvieron un ritmo estable durante toda la década (véase Cuadro II y Fig. 3).

Además de la tradición, entre las razones que explican este reparto podemos destacar la proximidad geográfica, la disponibilidad de buenas comunicaciones y la ausencia de otros centros de atracción próximos. Estas mismas razones son las que nos permiten entender el protagonismo de los murcianos en la inmigración extraprovincial de Elche. Cinco son los municipios de la provincia de Murcia que sobresalen por sus envíos de población: Fortuna, 
Abanilla, Murcia, Cartagena y Yecla. Para todos ellos la guerra supuso cambios en su ritmo emigratorio hacia Elche: para Abanilla conllevó un aumento espectacular que se continúa en la posguerra; los aportes de Fortuna cayeron drásticamente; Murcia y Yecla experimentaron un descenso transitorio; mientras que Cartagena conoció un crecimiento que no tuvo continuidad (véase Cuadro III).

Por lo que respecta a los escasos inmigrantes procedentes del extranjero, hemos de señalar que en su mayoría, como nos advierten sus apellidos eran hijos de españoles emigrados que retornaron. Francia y el Norte de África, zonas tradicionalmente receptoras

CUADRO III

ORIGEN MUNICIPAL DE LOS INMIGRADOS MURCIANOS EN ELCHE (en tantos por ciento)

\begin{tabular}{|lrrr|}
\hline Municipios & $\mathbf{1 9 3 0 - 3 5}$ & $\mathbf{1 9 3 6 - 3 9}$ & $\mathbf{1 9 3 9 - 4 0}$ \\
\hline Abanilla & 2,49 & 22,04 & 22,89 \\
Cartagena & 9,04 & 12,32 & 6,02 \\
Fortuna & 28,70 & 22,99 & 14,06 \\
Murcia & 17,69 & 12,80 & 16,47 \\
Yecla & 7,86 & 7,58 & 9,23 \\
Otros & 34,21 & 22,26 & 31,32 \\
Total & 100,00 & 100,00 & 100,00 \\
Total cifras absolutas & 763 & 422 & 249 \\
\hline
\end{tabular}

Cuadro IV

DISTRIBUCIÓN DE LOS INMIGRADOS EN ELCHE POR EDAD Y SEXO (en tantos por ciento)

\begin{tabular}{|lrrrrr|}
\hline & \multicolumn{5}{c}{$\mathbf{1 9 3 0 - 3 5}$} \\
& $\mathbf{0 - 2 0}$ & $\mathbf{2 1 - 4 0}$ & $\mathbf{4 1 - 6 5}$ & $\mathbf{6 6}$ y más & Total \\
\hline Varones & 17,6 & 16,9 & 11,0 & 0,8 & 1.300 \\
Mujeres & 19,4 & 20,8 & 11,9 & 1,4 & 1.502 \\
Total & 37,0 & 37,7 & 22,9 & 2,3 & 2.802 \\
\hline \multicolumn{7}{c}{$\mathbf{1 9 3 6 - 3 9}$} \\
\hline Varones & 19,3 & 14,9 & 9,6 & 0,9 & 795 \\
Mujeres & 22,3 & 20,2 & 10,8 & 1,9 & 980 \\
Total & 41,6 & 35,2 & 20,4 & 2,8 & 1.775 \\
\hline & & $\mathbf{1 9 3 9 - 4 0}$ & & \\
\hline Varones & 20,9 & 15,8 & 7,9 & 1,0 & 579 \\
Mujeres & 25,3 & 18,9 & 8,5 & 1,5 & 686 \\
Total & 46,2 & 34,8 & 16,4 & 2,5 & 1.265 \\
\hline
\end{tabular}


de emigrantes levantinos, son por ello también los principales lugares desde donde se producen estos retornos. Entre ambas acaparan más de las tres cuartas partes de los inmigrantes del exterior, el resto procedía de América Latina y otros países de Europa.

\section{Distribución por edad y sexo}

La población establecida en Elche durante los años treinta era muy joven, menor de 40 años en un $75 \%$ y con un índice de vejez extremadamente bajo (inferior a 7). Además, dentro de ella, el grupo de menores de 20 años sobresale con un porcentaje superior al $35 \%$, incluso entre los inmigrados llegados a principios de la década. Se trata, pues, de un fenómeno inmigratorio de tipo familiar; este carácter familiar, junto a la atracción que como núcleo urbano fabril necesitado de fuerza de trabajo femenino para la elaboración de la alpargata y otras actividades del sector servicios ejerce Elche, determina también una sex ratio favorable al elemento femenino, con valores que oscilan entre 80 y 90 (véase Cuadro IV).

\section{Actividad y profesiones de los inmigrantes}

El amplio número de inmigrantes se vio atraído por el auge económico ilicitano, asentado en la expansión de la industria del calzado. La tasa de población activa para todos los inmigrados de la época es del $44 \%$; no obstante, esta cifra hemos de considerarla con

Cuadro V

DISTRIBUCIÓN DE LOS INMIGRADOS EN ELCHE SEGÚN LA ACTIVIDAD DECLARADA (en tantos por ciento)

\begin{tabular}{|c|c|c|c|c|c|c|}
\hline \multicolumn{7}{|c|}{$1930-35$} \\
\hline & I & II & III & NO ACTIVOS & M.E.* & TOTAL \\
\hline Varones & 24,23 & 27,23 & 8,85 & 8,85 & 15,92 & 1.300 \\
\hline Mujeres & 3,06 & 17,11 & 62,38 & 62,38 & 12,32 & 1.502 \\
\hline Total & 12,88 & 26,44 & 37,50 & 37,50 & 14,00 & 2.802 \\
\hline \multicolumn{7}{|c|}{ 1936-39 } \\
\hline Varones & 29,06 & 26,54 & 8,18 & 8,18 & 24,65 & 795 \\
\hline Mujeres & 2,04 & 8,47 & 61,53 & 61,53 & 19,90 & 980 \\
\hline Total & 14,14 & 16,56 & 37,60 & 37,60 & 22,00 & 1.775 \\
\hline \multicolumn{7}{|c|}{$1939-40$} \\
\hline Varones & 18,65 & 19,69 & 7,94 & 7,94 & 31,26 & 579 \\
\hline Mujeres & 1,02 & 6,41 & 55,25 & 55,25 & 20,55 & 686 \\
\hline Total & 9,09 & 12,49 & 33,60 & 33,60 & 25,45 & 1.265 \\
\hline
\end{tabular}

* Mal especificados. 
FIGURA 4. Distribución de los inmigrados residentes en Elche en 1940 según el período de llegada y actividad declarada.

reservas, ya que durante los períodos de la contienda bélica y la postguerra es muy alto el número de personas que no indican su profesión, posiblemente porque aún no se habían estabilizado laboralmente. Además, la población femenina se declara mayoritariamente no activa de una forma tan absoluta que imposible concederle crédito; hemos de suponer, por tanto, que una elevada proporción de la población femenina trabajaba aunque no lo reconociese en el Padrón, más aún si tenemos en cuenta la facilidad para el trabajo a domicilio que la industria del calzado proporcionaba.

Observando la distribución por sectores económicos de los inmigrantes activos a lo largo de los tres períodos considerados, es fácil apreciar la existencia de un proceso de adaptación entre los llegados de fuera al carácter industrial de Elche: el sector secundario presenta entre los que se instalaron durante la guerra y la postguerra, cifras bajas, mientras que para los llegados anteriormente, es decir, para aquellos que más tiempo llevan residiendo en el municipio, los activos secundarios son mayoría (véase Cuadro V y Fig. 4).

Otro proceso que constatamos es el paulatino decrecimiento de los inmigrantes dedicados a las tareas agrícolas, si bien su número en cifras absolutas continúa siendo importante. Entre las causas que lo explican, quizás las más destacables sean la presencia ya de un numeroso contingente de jornaleros en el campo ilicitano, las escasas posibilidades de acceder a buenas tierras de cultivo y la preferencia por emplearse en otros sectores con mejores expectativas, especialmente entre los jóvenes.

Para la población femenina, cuyos datos hay que entender desde los recelos que anteriormente hemos señalado, el Padrón refleja como principales ocupaciones las del sector secundario y de servicios. Antes de la guerra, son mayoría las mujeres dedicadas a 
las actividades manufactureras, y esta tendencia se mantiene, aunque moderada durante los años del conflicto, para pasar - al menos oficialmente- a un claro predominio del sector terciario entre las llegadas en la posguerra.

En general, los activos del sector secundario aparecen acaparados en gran medida por la industria del calzado. En el sector terciario, sin embargo, hemos de hacer una distinción por sexos, ya que si el grueso de los varones se concentra en el comercio, los servicios administrativos y el transporte, entre las mujeres es el servicio doméstico la profesión más desempeñada. Por otra parte, entre los varones debe mencionarse el incremento que experimentan tras la guerra los dedicados a tareas de orden público, consecuencia del cambio de régimen y la necesidad de un personal fiel al nuevo Gobierno.

La dedicación laboral de los inmigrantes está ligada en muchos casos a su lugar de procedencia, y esto lo podemos comprobar analizando a los llegados desde los tres focos principales de emigración a Elche: la provincia de Murcia y la comarca alicantina del Bajo Segura, con un marcado carácter agrario, envían predominantemente agricultores y jornaleros; mientras que el Vinalopó Medio, comarca con centros fabriles de cierta consideración, es el origen de una corriente de gentes que se emplean directamente en la industria.

\section{Lugares de residencia de los inmigrados}

Los inmigrados que se establecen en Elche durante la década de los años treinta están ubicados preferentemente en el casco urbano, aunque - como podemos constatar a través de las fechas de llegada que registra el Padrón de 1940 — la atracción ejercida por el campo fue creciendo progresivamente (véase Cuadro VI). Dentro de la ciudad, esta población inmigrada se distribuía de manera uniforme, de modo que no existió discriminación entre barrios por lugares de origen. En cualquier caso, se puede señalar una mayor presencia de inmigrantes en la parte de la ciudad situada a la izquierda del río Vinalopó, es decir, en el núcleo urbano tradicional, donde las posibilidades de encontrar viviendas baratas eran mayores. En el campo, las partidas donde mayor porcentaje de inmigrantes se asentó fueron las de Altabix, Huertos y Molinos, y Carrús, lugares próximos al casco urbano y por los que no tardaría en expandirse el mismo.

La distribución de los inmigrados dentro del municipio también estaba relacionada con el lugar de origen y la actividad profesional. Así, los originarios de la provincia de Murcia y del Bajo Segura, manifiestan una clara preferencia por el campo, mientras que los procedentes del Medio Vinalopó fijan su residencia en la ciudad.

CUADRO VI

UBICACIÓN DE LOS INMIGRADOS EN ELCHE

(en tantos por ciento)

\begin{tabular}{|lrrr|}
\hline & $\mathbf{1 9 3 0 - 3 5}$ & $\mathbf{1 9 3 6 - 3 9}$ & $\mathbf{1 9 3 9 - 4 0}$ \\
\hline Campo & 23,68 & 35,72 & 41,21 \\
Ciudad & 76,21 & 64,28 & 58,79 \\
Total & 100,00 & 100,00 & 100,00 \\
Total cifras absolutas & 2.802 & 1.775 & 1.265 \\
\hline
\end{tabular}




\section{Inmigrantes forzados}

Entre las personas llegadas a Elche tras la guerra encontramos dos colectivos de características muy especiales: los presos políticos encarcelados en una antigua fábrica habilitada como prisión y un destacamento militar encargado de evitar cualquier movimiento subversivo por parte de una población leal a la República hasta su derrota.

En la prisión provisional, además de los reclusos ilicitanos, había seiscientos setenta reos procedentes, en su mayor parte, del resto de la provincia de Alicante $(60 \%) \mathrm{y}$, en menor medida, de Castellón (8\%), Murcia (4,5\%), Madrid (4\%), Toledo (2\%), Valencia (2\%) y otras provincias españolas. Los prisioneros alicantinos llegan, sobre todo, de las comarcas del Bajo Segura y Vinalopó Medio, aunque aparecen representadas todas las comarcas y ciudades importantes. Se trata, en general, de varones adultos jóvenes (más del $60 \%$ tiene una edad comprendida entre los 20 y los 40 años de edad) y que antes de ser privados de libertad trabajan casi todos; un $40 \%$ en el sector primario (más como labradores que como jornaleros), un $34 \%$ en el secundario y un $24 \%$ en el sector servicios.

El otro colectivo de «inmigrantes forzados» era un destacamento del Ejército de Tierra, compuesto por 116 hombres, en su mayoría jóvenes que estaban cumpliendo el servicio militar, originarios de fuera de la provincia y en general de zonas donde la causa «nacional» había encontrado firme arraigo. 